\title{
Pomegranate Polyphenols and Resveratrol Protect the Neonatal Brain against Hypoxic-Ischemic Injury
}

\author{
Tim West ${ }^{a, b}$ Madeliene Atzevaa ${ }^{a, b}$ David M. Holtzman ${ }^{a-c}$ \\ ${ }^{a}$ Department of Neurology, ${ }^{\mathrm{b}}$ Hope Center for Neurological Disorders and ${ }^{\mathrm{C}}$ Molecular Biology and Pharmacology, \\ Washington University School of Medicine, St. Louis, Mo., USA
}

\section{Key Words}

Pomegranate juice $\cdot$ Polyphenols $\cdot$ Resveratrol $\cdot$

Hypoxic-ischemic injury $\cdot$ Caspase 3 activation

\begin{abstract}
A previous study from our lab has shown that the polyphenol-rich pomegranate juice can protect the neonatal mouse brain against hypoxic-ischemic $(\mathrm{H}-\mathrm{I})$ injury when given to mothers in their drinking water. To test the hypothesis that this protection is due to the polyphenols in the juice, we studied the effects of the pomegranate polyphenol extract in the same neonatal $\mathrm{H}-\mathrm{I}$ model. To further explore the role of a specific polyphenol in neonatal $\mathrm{H}-\mathrm{I}$ we investigated the effects of resveratrol. The neuroprotective effects of resveratrol have been demonstrated in adult models of stroke, but had not previously been examined in neonates. We show that pomegranate polyphenols and resveratrol reduce caspase- 3 activation following neonatal $\mathrm{H}-\mathrm{I}$. Resveratrol reduced caspase- 3 activation when given before the injury but not when given $3 \mathrm{~h}$ after the injury. In addition to preventing caspase-3 activation, resveratrol also reduced cal pain activation. Finally, we show that resveratrol can protect against tissue loss measured at 7 days after the injury. These and other recent findings suggest that polyphenols should be further investigated as a potential treatment to decrease brain injury due to neonatal $\mathrm{H}-\mathrm{I}$.

Copyright $\odot 2007$ S. Karger AG, Basel
\end{abstract}

\section{KARGER}

Fax +4161306 1234

E-Mail karger@karger.ch

www.karger.com
(C) 2007 S. Karger AG, Basel

Accessible online at: www.karger.com/dne

\section{Introduction}

Neonatal hypoxia-ischemia (H-I) is a major cause of morbidity and mortality in human newborns with motor and cognitive sequelae frequently seen in survivors [Robertson et al., 1989; Shankaran et al., 1991; Volpe, 1995; Back, 2001]. Recent advances in neonatal care have improved the survival of severely prematurely born babies. These very low birth weight babies have a greatly increased risk of perinatal brain injury, including hypoxicischemic brain injury [Back and Rivkees, 2004; GieronKorthals and Colon, 2005]. Neonatal H-I has been associated with increases in reactive oxygen species, and recent studies suggest that new avenues of treatments of neonatal H-I should include selective responses to the generation of oxidative damage [Singh et al., 1999; Hamrick and Ferriero, 2003; Gulcan et al., 2005]. Current clinical treatments that appear successful in initial studies include hypothermia, which is thought to slow down the neuronal cell death processes and attenuate the generation of reactive oxygen species [Kil et al., 1996; Thoresen et al., 1997; Hashimoto et al., 2003; Gluckman et al., 2005; Shankaran et al., 2005].

Our lab and others have utilized an animal model of neonatal H-I in mice to determine mechanisms of injury as well as address potential treatments [Gibson et al., 2001; Han et al., 2001; West et al., 2006]. In a recent study using this model, we found that continuous pre- and postinjury ingestion of pomegranate juice by the dam

David M. Holtzman

Washington University, Department of Neurology Box 8111 660 S Euclid

Saint Louis, MO 63110 (USA)

Tel. +1 314747 0286, Fax +1 314362 2826, E-Mail holtzman@neuro.wustl.edu 
leads to significant protection of the neonatal brain [Loren et al., 2005]. The mechanism of neuroprotection afforded by pomegranate juice is unknown but it could potentially involve the antioxidant or other properties of polyphenols.

One of the most well studied polyphenols is resveratrol which is found in grapes, several types of nuts and kojohkon (Japanese Knotweed), an oriental medicine used to treat diseases of the blood vessels [Sato et al., 1997; Faustino et al., 2003; Tokusoglu et al., 2005]. Resveratrol is an antioxidant but its in vivo effects reach far beyond that of other antioxidants. Most famously, resveratrol is thought to be the compound responsible for the low incidence of heart disease in the French population due to the high intake of red wine in France [Kopp, 1998]. Besides cardiovascular effects, resveratrol may have prophylactic effects against other human diseases, such as cancer [Bianchini and Vainio, 2003] and dementia [Leibovici et al., 1999; Truelsen et al., 2002]. In rats, resveratrol has been studied extensively in adult models of stroke and has been found to protect the brain when the rodents have been pre-treated for 3 weeks or longer with resveratrol containing drinking water [Virgili and Contestabile, 2000] or when resveratrol is administered by interperitoneal injection [Huang et al., 2001; Gupta et al., 2002; Sinha et al., 2002]. However, there have to our knowledge been no studies looking at the neuroprotective effects of resveratrol in neonatal brain injury.

In this study, we found that pomegranate polyphenol extract (PPE) as well as resveratrol can protect the neonatal rodent brain against H-I brain injury. When administered before injury, resveratrol can protect against both caspase- 3 activation at $24 \mathrm{~h}$ after the injury and tissue loss at 7 days after injury. These studies suggest that polyphenols should be considered for further evaluation as potential treatments to lessen the effects of neonatal H-I brain injury.

\section{Materials and Methods}

\section{Animals and Surgical Procedures}

All rats and mice were kept under 12/12 light/dark cycles with ad libitum access to food and water. For studies of polyphenol extract of pomegranates and resveratrol in mice, male and female C57BL/6-J mice were interbred. For pups used in H-I experiments, the date of delivery was noted and at postnatal day 7 (P7) the pups underwent hypoxia-ischemia as described [Gibson et al., 2001; Han et al., 2001; West et al., 2006]. Briefly, mice were anaesthetized by inhalation of $5 \%$ halothane (balance room air) for induction and $1.5 \%$ for maintenance. An incision was made on the left side of the neck and the carotid artery isolated, exposed and permanently ligated. The pups were then put at $37^{\circ} \mathrm{C}$ to wake up and finally returned to the dam for a $2 \mathrm{~h}$ recovery period. Hypoxia was induced by putting pups in temperature-controlled chambers $\left(37^{\circ} \mathrm{C}\right)$ through which humidified $8 \%$ oxygen flowed for $45 \mathrm{~min}$. A similar protocol was used to induce H-I injury in P7 Sprague-Dawley rats; however, for the surgery on rats $2 \%$ halothane was required for maintenance of anesthesia and the rat pups were subjected to $8 \%$ oxygen for $2.5 \mathrm{~h}$.

\section{PPE Ingestion}

The pomegranate polyphenol-enriched extract (PPE) was obtained from Pom Wonderful. PPE was produced from the skin and the aril of Punica granatum L. Wonderful variety and contains $0.9 \mathrm{mg}$ polyphenols per mg powder. $96 \mathrm{mg}$ of PPE was diluted in $100 \mathrm{ml}$ of sugar water containing the same sugar composition as used in the previous experiments with pomegranate juice (a 1:160 dilution of $12.4 \%$ sucrose, $1.1 \%$ fructose and $1.1 \%$ glucose) [Loren et al., 2005]. This corresponds to an adult mouse ingesting $4.8 \mathrm{mg}$ polyphenols per day (each mouse drinks about $5 \mathrm{ml}$ of water per day). This dose of polyphenols was estimated to be similar to the amount of polyphenols ingested by mice drinking pomegranate juice in our previous study [Loren et al., 2005]. PPE diluted in sugar water or straight sugar water alone was given to the pregnant females as the sole source of drinking water throughout pregnancy and following the delivery, for the duration of the life of the pups. Drinking water was prepared fresh twice a week and kept in UV opaque bottles to prevent breakdown of the polyphenols. Since littermate controls were not possible for this experiment, we used 4 litters for each group to minimize the effect of litter to litter variability.

\section{Resveratrol and Vehicle Injections}

Before each experiment, resveratrol (Cayman Chemicals) was freshly dissolved in $100 \%$ dimethyl sulfoxide (DMSO, Sigma) at a final concentration of $70 \mathrm{mg} / \mathrm{ml}$. At this concentration, a 3.5gram mouse would receive a $1-\mu l$ injection to give a final concentration of $20 \mathrm{mg} / \mathrm{kg}$ (high dose). For $200-\mu \mathrm{g} / \mathrm{kg}$ (medium-dose) and $2-\mu \mathrm{g} / \mathrm{kg}$ (low-dose) injections the $70 \mathrm{mg} / \mathrm{ml}$ stock was diluted $1: 100$ and 1:10,000, respectively. Drug or vehicle was injected into the intraperitoneal space using a 26-gauge needle and a 5 - $\mu 1$ Hamilton syringe (Hamilton). For initial studies in mice, 3 different time points of injection were chosen: $24 \mathrm{~h}$ before the start of the hypoxic episode, $10 \mathrm{~min}$ before hypoxia or $3 \mathrm{~h}$ after completion of the hypoxic episode. At each time point, half the litter would be injected with one concentration of resveratrol and the other half injected with vehicle (DMSO) alone. All rats were injected with $20 \mathrm{mg} / \mathrm{kg}$ at $10 \mathrm{~min}$ before injury, or $3 \mathrm{~h}$ after injury using a freshly prepared $70 \mathrm{mg} / \mathrm{ml}$ stock as for mice.

\section{Tissue Lysis and DEVD Cleavage Activity}

At $24 \mathrm{~h}$ following the end of the hypoxic episode, mice and rats were sacrificed by lethal injection of $200 \mathrm{mg} / \mathrm{kg}$ pentobarbital. Following transcardial perfusion with heparinized saline, the brains were extracted and the left and right hippocampi dissected on ice and frozen using dry ice. For each individual experiment, left and right hippocampi from all animals were lysed on the same day in the same lysis buffer (Cell Signaling) containing protease inhibitor cocktail (Roche). Lysates were cleared by spinning at $20,000 \mathrm{~g}$ for $15 \mathrm{~min}$ at $4^{\circ} \mathrm{C}$. Protein concentration in each lysate was determined using a BCA kit (Pierce) and DEVD cleavage ac- 
tivity determined as described [West et al., 2006]. Briefly, lysates were incubated with DEVD-AMC (Calbiochem) in assay buffer (10 mM HEPES, pH 7.4, $42 \mathrm{~mm} \mathrm{KCl,} 5 \mathrm{mM} \mathrm{MgCl}_{2}, 3 \mathrm{~mm} \mathrm{DTT}$, and $10 \%$ sucrose) and fluorescence was measured every 5 min using a fluorescence plate reader (BioTek). DEVD cleavage activity was normalized to total protein concentration for each lysate and is reported as pmol AMC generated per mg total protein per minute.

\section{Western Blotting}

Remaining tissue lysates from the hippocampi that had been used for DEVD cleavage assays were pooled together into groups containing lysates from 4 individual mice. Based on protein concentration, each pool contains the same amount of protein lysate from the left or right hippocampus of 4 different mice. This allows for comparison of lysates from several different mice on the same gel. For Western blotting, $20 \mu \mathrm{g}$ of total protein per lane was separated on a $4-12 \%$ Bis-Tris NuPage gel (Invitrogen). Proteins were transferred onto Immobilon $\mathrm{P}$ membranes (Millipore) and blocked in 2\% ECL blocking reagent (Amersham). Membranes were then incubated with primary antibody overnight. Antibodies used were: Spectrin (1:1k, Chemicon), tubulin (1:4k, Sigma). Membranes were then incubated with HRP-labeled secondary antibody, developed using SuperSignal (Pierce), and visualized on an ImageStation (Kodak).

\section{Histology and Tissue Loss Calculation}

For histological assessment of the extent of H-I injury, mice were sacrificed at P14 and their brains extracted and sectioned into $50-\mu \mathrm{m}$ sections. Slices $300-\mu \mathrm{m}$ apart were mounted, stained with cresyl violet and digitized on an Expression 1680 transparency scanner (Epson). Percentage volume loss in the hippocampus, cortex and striatum was calculated by comparing the area of remaining tissue in the injured and noninjured hemispheres as described [West et al., 2006]. For hippocampal tissue loss, 6 consecutive sections were measured, for cortical tissue loss 4 consecutive sections were measured and for striatal tissue loss 2 consecutive sections were measured.

\section{Statistics}

All data are presented as mean \pm SEM and comparisons between drug and vehicle groups were done using a t test if the data were parametric, or a Mann-Whitney $U$ test for nonparametric data. Statistical significance was set at $p<0.05$. Statistics were performed using GraphPad Prism (GraphPad Software, Inc.).

\section{Results}

Ingestion of PPE by the Dam Lowers Caspase-3

Activation in Hippocampus of Pups following

Neonatal H-I

Pregnant female mice were given either vehicle (sugar water) or PPE in vehicle as the sole supply of drinking water during pregnancy and following delivery. Neonatal H-I was performed on the pups at postnatal day 7 (P7) and the pups were sacrificed $24 \mathrm{~h}$ following the injury.

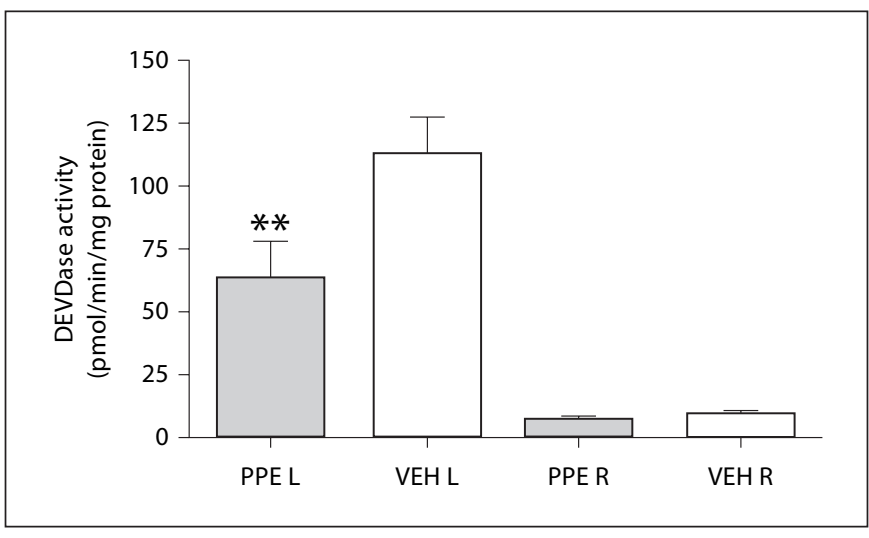

Fig. 1. PPE protects against caspase-3 activation following neonatal H-I. Female mice had their drinking water replaced with either sugar water (vehicle, VEH) or sugar water containing the PPE during pregnancy and following delivery. Pups from these dams were subjected to neonatal $\mathrm{H}-\mathrm{I}$ at $\mathrm{P} 7$ and caspase-3 activity was measured in the left (L) and right (R) hippocampus at $24 \mathrm{~h}$ following the injury by DEVD cleavage assay. Pups of dams drinking PPE $(n=25)$ had significantly less caspase-3 activation in the left hippocampus than pups of dams drinking sugar water $(\mathrm{VEH}, \mathrm{n}=$ 21). ${ }^{* *} \mathrm{p}=0.0024$ comparing PPE vs. vehicle-treated mice.

Caspase- 3 activity (measured as rate of DEVD cleavage) was measured in the left and right hippocampus. In this model of neonatal H-I in our prior studies, the majority of tissue loss and cell death is in the hippocampus with $\sim 40 \%$ tissue loss 7 days after $\mathrm{H}-\mathrm{I}, \sim 20 \%$ tissue loss in the striatum, and $\sim 5 \%$ in the cortex [Han et al., 2001; West et al., 2006]. In previous studies using this model, caspase-3 activation in the hippocampus has been shown to correlate well with injury in other brain regions [Han et al., 2001; West et al., 2006]. Caspase-3 activation is a reliable and readily quantifiable measure of the extent of apoptotic neuronal cell death in response to neonatal H-I injury [Han et al., 2000; Gibson et al., 2001]. Thus, we assessed caspase- 3 activation in the hippocampus after H-I. Pups of dams that have been administered PPE had significantly less caspase-3 activity in the hippocampus than did pups of dams subjected to sugar water alone (fig. 1). This suggests that the polyphenols in the pomegranate juice were responsible for the neuroprotection observed in the previous study.

\section{Resveratrol Protects against Caspase- 3 and Calpain Activation in Mice in a Dose- and Time-Dependent Manner}

To further explore the role of polyphenols in protecting the neonatal brain following neonatal H-I, we inves- 
Fig. 2. Resveratrol protects the neonatal brain against $\mathrm{H}$-I-induced caspase-3 activation in a time- and dose-dependent manner. At different time points before or after injury, littermate mouse pups were injected interperitoneally with vehicle (DMSO) or resveratrol at high $(20 \mathrm{mg} / \mathrm{kg})$, medium $(200 \mu \mathrm{g} / \mathrm{kg})$ or low $(2 \mu \mathrm{g} / \mathrm{kg})$ doses. Caspase-3 activation was measured as DEVD cleavage activity in the injured hippocampus at $24 \mathrm{~h}$ following neonatal $\mathrm{H}-\mathrm{I}$ injury given at $\mathrm{P} 7$. The number of animals in each treatment group is indicated inside each bar in the graph: 55 pups were given either resveratrol or vehicle at $24 \mathrm{~h}$ before injury, 74 pups were given resveratrol or vehicle $10 \mathrm{~min}$ before injury, and 64 mice were treated with resveratrol or vehicle $3 \mathrm{~h}$ after injury. There is no difference in DEVD cleavage activity in the noninjured hippocampus, data not shown for clarification. a If injected at $24 \mathrm{~h}$ before hypoxia, resveratrol protects against caspase- 3 activation in the hippocampus in a dose-dependent manner, when compared to littermate mice injected with vehicle. The high and the medium dose of resveratrol significantly reduce the amount of caspase- 3 activation, while the low dose of resveratrol does not provide significant protection. b If injected $10 \mathrm{~min}$ before hypoxia resveratrol reduces caspase- 3 activation at the high and medium doses, but not at the low dose. c When injected at $3 \mathrm{~h}$ after injury, resveratrol does not reduce caspase- 3 activity at any of the doses utilized. ${ }^{*} \mathrm{p}<0.05$ and ${ }^{* *} \mathrm{p}<0.01$ resveratrol vs. vehicle-injected littermates.

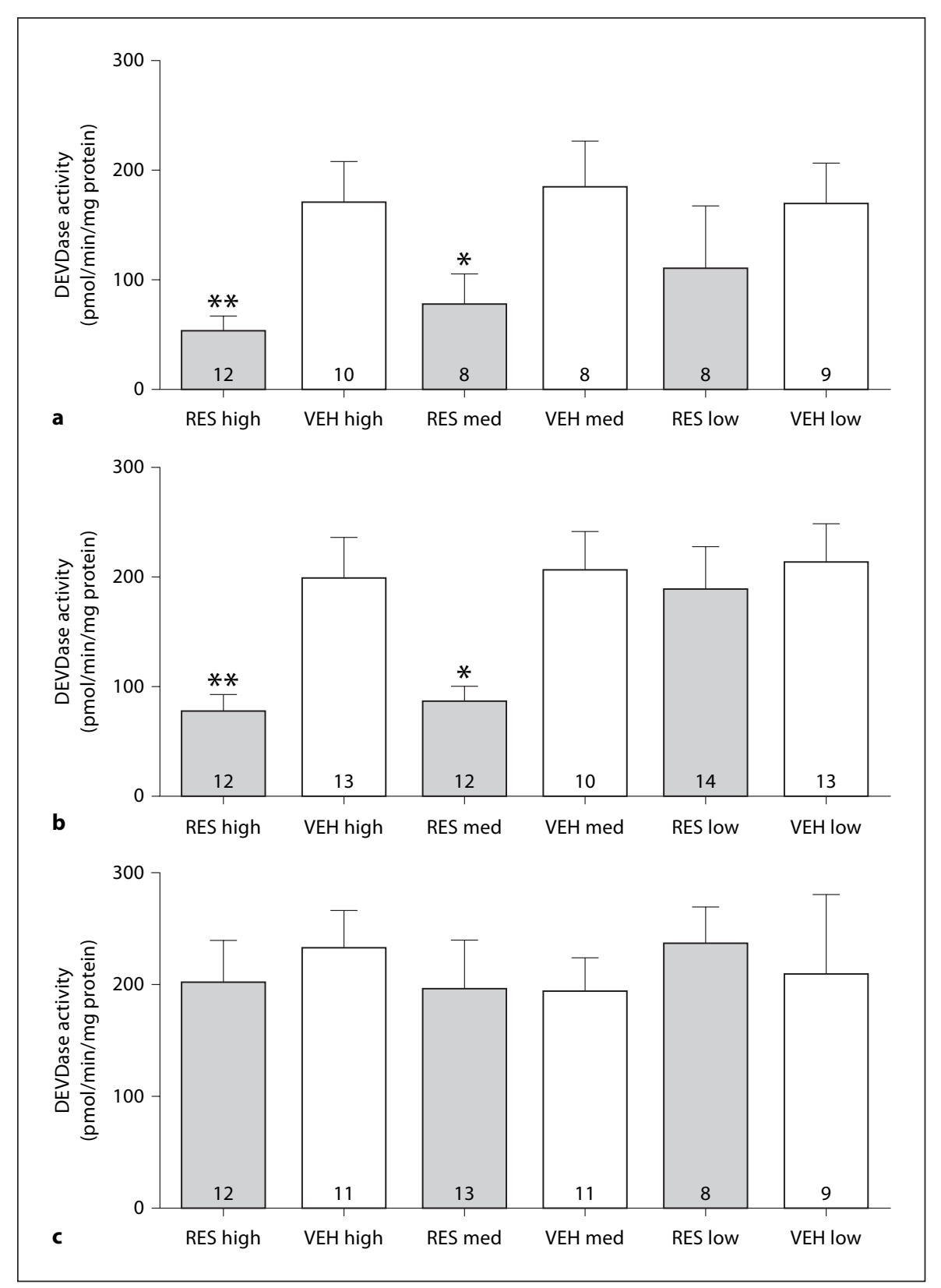

tigated the effect of the specific polyphenol resveratrol. Previous studies using resveratrol in adult rat stroke models have focused on high concentrations and the effect of treatment before the injury. Since the effect of resveratrol has not been tested in neonatal H-I model, we wanted to investigate the dose and time dependence of protection by resveratrol in this injury paradigm in mice. We tested 3 different concentrations of resveratrol: 20 $\mathrm{mg} / \mathrm{kg}, 200 \mu \mathrm{g} / \mathrm{kg}$ and $2 \mu \mathrm{g} / \mathrm{kg}$. These concentrations were administered at 3 different time points: $24 \mathrm{~h}$ before the start of hypoxia, 10 min before the start of hypoxia, and $3 \mathrm{~h}$ after hypoxia. As an indicator of the level of injury we measured caspase- 3 activity at $24 \mathrm{~h}$ after injury. When administered $24 \mathrm{~h}$ before the hypoxic insult, resveratrol decreased DEVD cleavage activity in a dose-dependent manner, with $20 \mathrm{mg} / \mathrm{kg}$ and $200 \mu \mathrm{g} / \mathrm{kg}$ being significantly protective against caspase- 3 activation and $2 \mu \mathrm{g} / \mathrm{kg}$ having no significant effect (fig. 2a). If administered 10 min before injury, resveratrol is protective in the same concentration-dependent manner as if adminis- 
Fig. 3. Resveratrol reduces caspase- 3 and calpain cleavage of spectrin following neonatal H-I. Spectrin cleavage products were investigated at $24 \mathrm{~h}$ after injury in mice injected with $20 \mathrm{mg} / \mathrm{kg}$ resveratrol or vehicle at $10 \mathrm{~min}$ before exposure to hypoxia and after carotid ligation. Pooled lysates from 4 different animals were run in each lane. Injured (left, L) hippocampus or noninjured (right, R) were run side by side on SDS PAGE and probed with antibodies against spectrin. Spectrin is cleaved by calpain to give rise to a p150 and a p145 band and by caspase- 3 to give rise to a p120 band. These bands are strongly present in lysates from vehicle-injected mice but to a much lesser extent in lysates from resveratrol-injected mice. Relative intensity of the p150 and p145 bands was calculated by comparison to the intensity of the tubulin loading control. The intensities of the p150 and p145 bands were significantly reduced in the mice that had received resveratrol injection, suggesting that calpain activation is prevented by resveratrol. ${ }^{* * *} \mathrm{p}<$ 0.001 resveratrol vs. vehicle by t test.

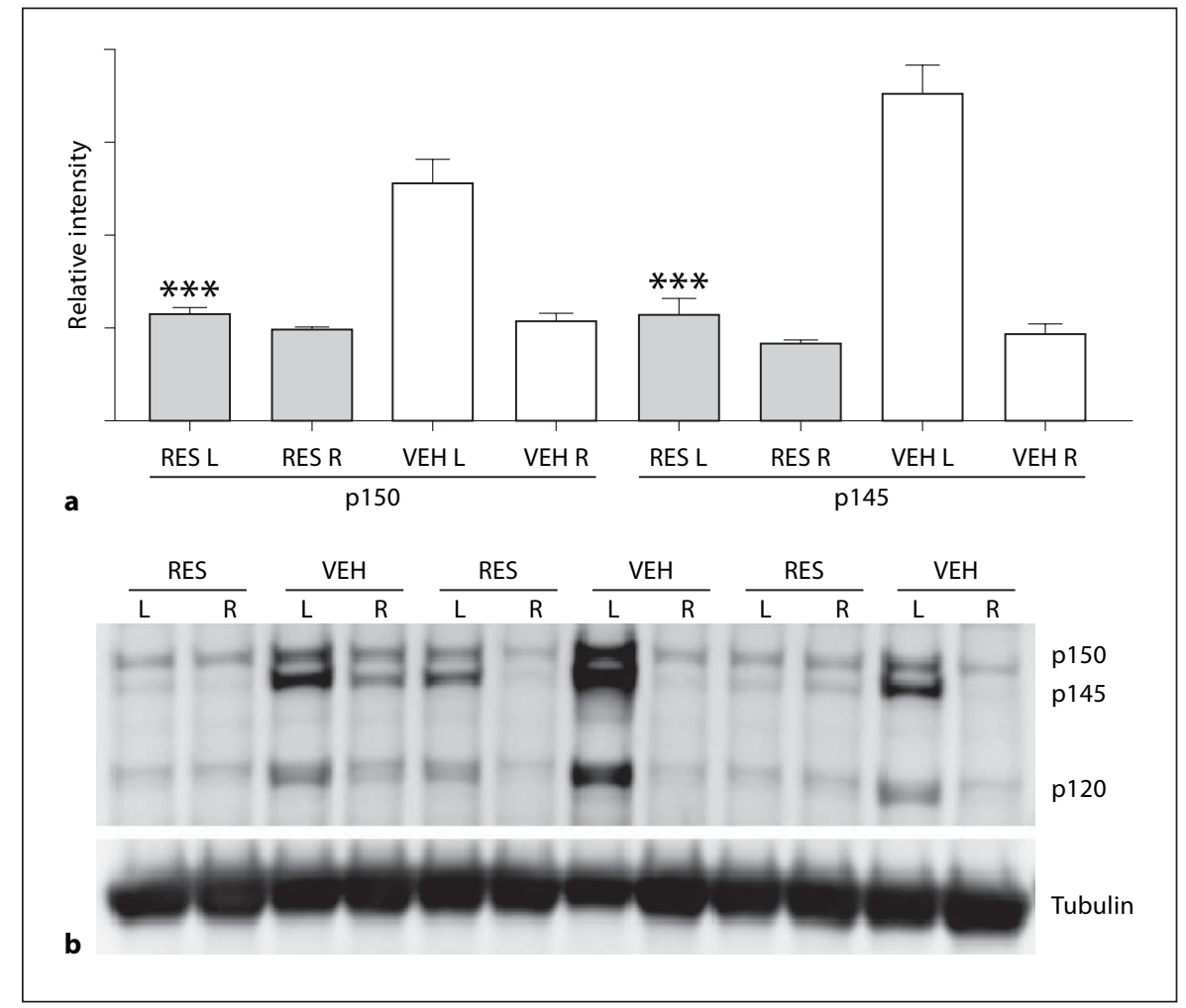

tered $24 \mathrm{~h}$ prior to injury (fig. 2b). However, when administered $3 \mathrm{~h}$ after injury, resveratrol has no effect on caspase-3 (fig. 2c). The level of protection is the same at 20 $\mathrm{mg} / \mathrm{kg}$ and $200 \mu \mathrm{g} / \mathrm{kg}$, showing that resveratrol could potentially protect at physiologically relevant levels. Interestingly, resveratrol is protective even when given at $24 \mathrm{~h}$ before the injury. This could either be due to slow metabolism of resveratrol [Yu et al., 2002] in the mouse pup or that resveratrol can mimic the effects of preconditioning, as shown in a rat brain slice model of ischemia [Raval et al., 2006]. To see if there was a difference in protection afforded by resveratrol administered at different time points, we compared the level of caspase- 3 activation between time points by one-way ANOVA. While caspase- 3 activation in mice receiving preinjury administration is significantly different from postadministration, there is no statistical difference in the results obtained when resveratrol was administered either $24 \mathrm{~h}$ or $10 \mathrm{~min}$ prior to H-I.

To further investigate the cell death pathways inhibited by resveratrol, we investigated calpain activation in the injured and noninjured hippocampus following H-I. Spectrin is cleaved by both calpain and caspase-3, giving rise to specific cleavage products, p145 and p150 for cal- pain and p120 for caspase-3. We have previously shown that calpain cleavage of spectrin is caspase- 3 independent [Han et al., 2002; West et al., 2006]. Thus, calpain cleavage of spectrin is a measure of a nonapoptotic and likely necrotic type of cell death. In brain lysates assessed $24 \mathrm{~h}$ after $\mathrm{H}-\mathrm{I}$, the calpain cleavage products of spectrin were markedly decreased in the hippocampus of mice that had received resveratrol $10 \mathrm{~min}$ before the onset of hypoxia (figure 3). This shows that in addition to decreasing apoptotic cell death, resveratrol also decreases the amount of necrotic cell death following $\mathrm{H}-\mathrm{I}$.

\section{Resveratrol Protects the Neonatal Brain against Tissue} Loss following $\mathrm{H}-\mathrm{I}$

To correlate the decrease in molecular markers of apoptosis and necrosis in mice injected with resveratrol with longer term protection of the brain, we measured the percentage tissue loss at P14. For this study, littermate mice received either $20 \mathrm{mg} / \mathrm{kg}$ resveratrol or vehicle at 10 min before the start of the hypoxic period at P7. At 7 days after injury (P14), the mice were sacrificed and their brains extracted and processed for histological analysis. Percentage volume tissue loss was calculated by comparing the ipsi- and contralateral areas of the brain in con- 


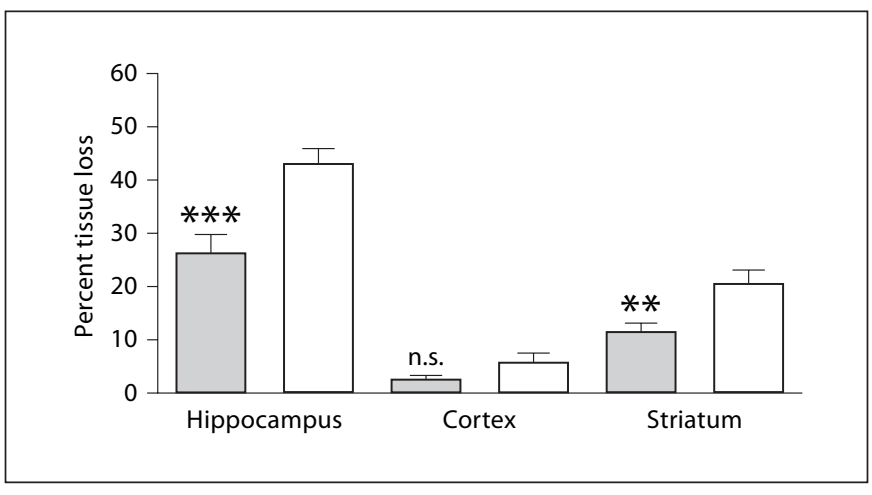

Fig. 4. Resveratrol decreases the amount of tissue loss at P14. P7 mice were injected with resveratrol $(\square ; n=24)$ or vehicle $(\square ; n=$ 26) following carotid ligation and $10 \mathrm{~min}$ before hypoxia and tissue loss was assessed at 7 days after injury. This is a good measure of overall brain injury following neonatal H-I. Percentage tissue loss was determined by comparing the area of the brain region in the left and the right hemisphere through several serial coronal brain sections as described in the 'Materials and Methods' section. When compared to mice injected with vehicle, mice receiving resveratrol were significantly protected against tissue loss in the hippocampus and striatum. Resveratrol also appears to protect the cortex, but this protection is not statistically significant $(\mathrm{p}=0.1) .{ }^{* *} \mathrm{p}<0.01$ and ${ }^{* * *} \mathrm{p}<0.001$ resveratrol vs. vehicle injected littermates.

secutive coronal sections $300-\mu \mathrm{m}$ apart. We have previously shown that this is an accurate way to measure the amount of tissue lost following neonatal H-I injury [Cheng et al., 1997; West et al., 2006]. Administration of $20 \mathrm{mg} / \mathrm{kg}$ of resveratrol resulted in significant protection against tissue loss in the hippocampus and striatum (fig. 4). There is also a decrease in the cortical tissue loss; however, this is not statistically significant due to the low amount of injury in the cortex.

\section{Resveratrol Reduces Caspase-3 Activation in the Hippocampus of Neonatal Rats following H-I}

The patterns and mechanisms of brain injury in the neonatal rat and mouse are similar but not the same. To further investigate the neuroprotective effects of resveratrol, we tested the ability of resveratrol to inhibit caspase3 activation in a rat model of neonatal H-I. Although neonatal $\mathrm{H}-\mathrm{I}$ injury in our protocol is performed at $\mathrm{P} 7 \mathrm{in}$ both rats and mice, it is likely that the brain of the two rodents are at slightly different developmental stages at this age [Hagberg et al., 1997]. An example of differences between species is that minocycline has been found to be neuroprotective in the rat but not in the mouse neonatal H-I

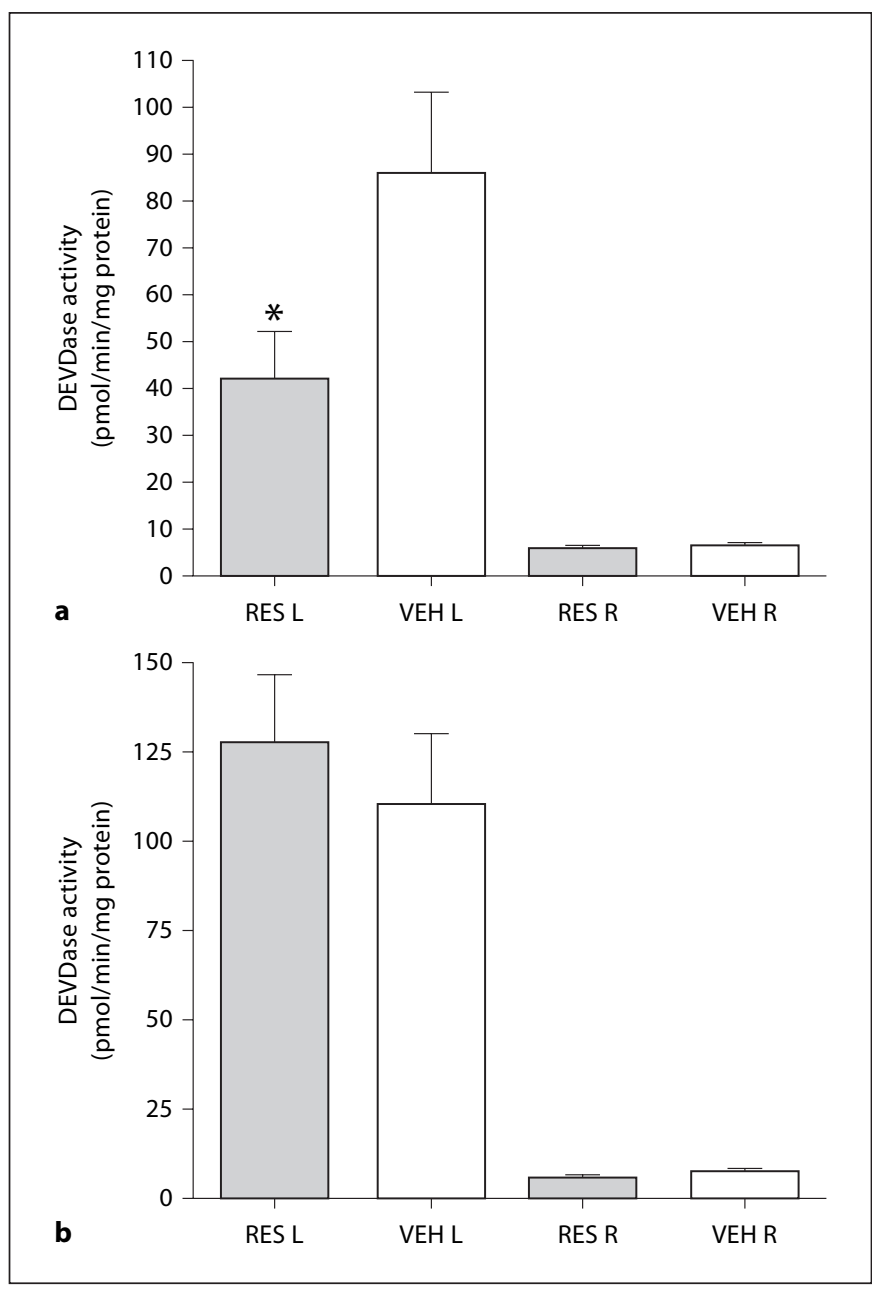

Fig. 5. Resveratrol protects the neonatal rat brain against caspase3 activation following $\mathrm{H}-\mathrm{I}$ injury. Rats underwent neonatal $\mathrm{H}-\mathrm{I}$ at P7 and were injected with $20 \mathrm{mg} / \mathrm{kg}$ resveratrol or vehicle following carotid ligation and $10 \mathrm{~min}$ before hypoxia (a) or $3 \mathrm{~h}$ after hypoxia (b). DEVD cleavage activity was measured at $24 \mathrm{~h}$ after injury in hippocampal lysates. As seen in the mice, rats that received resveratrol before injury are protected against caspase-3 activation following neonatal $\mathrm{H}$-I. Due to a higher incidence of no detectable caspase- 3 activation following neonatal $\mathrm{H}-\mathrm{I}$ in rats, a larger number of rats were enrolled in this study to determine whether there was a statistical difference between resveratroltreated $(n=18)$ and vehicle-treated $(n=16)$ rats. ${ }^{*} \mathrm{p}<0.05$ resveratrol vs. vehicle injected littermates. When administered $3 \mathrm{~h}$ after hypoxia, there was no significant difference in tissue loss between rats that received resveratrol $(n=19)$ vs. vehicle $(n=18)$.

model [Tsuji et al., 2004]. Also, the time course of caspase- 3 activation in rats and mice following neonatal H-I is different [Cheng et al., 1998; Han et al., 2001]. Finally, there is a difference in the fatality rate during exposure to hypoxia between rats and mice. In mice the fatality rate 
is below $10 \%$, probably because the hypoxic episode is relatively short. However, in our protocol that results in a similar amount of brain injury, rats are hypoxic for 150 min and this is associated with a higher fatality rate. In this study, 4 of $22(18 \%)$ rats injected with resveratrol died during hypoxia while 6 of $22(27 \%)$ of rats injected with vehicle died during hypoxia.

To test if resveratrol specifically protects the neonatal rat brain, we measured caspase- 3 activation at $24 \mathrm{~h}$ following neonatal $\mathrm{H}-\mathrm{I}$ in rats. We found that administration of $20 \mathrm{mg} / \mathrm{kg}$ resveratrol to rats $10 \mathrm{~min}$ before the start of the hypoxic period leads to a significant decrease in caspase- 3 activation in rat pups as it did in mice (fig. 5a). We also tested if $20 \mathrm{mg} / \mathrm{kg}$ of resveratrol is protective when administered $3 \mathrm{~h}$ after the injury since the time course of caspase- 3 activation is different between rats and mice and since there has been reports of neuroprotective agents working in the rat when administered after the injury [Wei et al., 2004; Shin et al., 2006]. However, at this time point, resveratrol is not protective against caspase-3 activation (fig. 5b). Thus, it appears that resveratrol protection of the rat brain follows similar time dependence as in the mouse brain.

\section{Discussion}

Dietary supplementation with foods rich in polyphenols - pomegranates, blueberries, green tea, and apple juice - has been shown to provide neuroprotection in animal models of focal brain ischemia, of periventricular white matter injury, and of Alzheimer's disease [Levites et al., 2001; Sweeney et al., 2002; Dajas et al., 2003; Etus et al., 2003; Ortiz and Shea, 2004; Loren et al., 2005; Hartman et al., 2006]. Polyphenols have been found to possess antioxidant properties as well as to have effects on gene expression [Kostrzewa and Segura-Aguilar, 2003]. Specifically, one polyphenol, resveratrol, has been shown to increase activity of members of the sirtuin gene class, blunting p53 action and blocking apoptosis [Latruffe et al., 2002; Hall, 2003; Howitz et al., 2003]. Recent studies indicate that among foods that contain polyphenols, juice extracted from the pomegranate has the highest concentration of measurable polyphenols [Gil et al., 2000; Kelawala and Ananthanarayan, 2004]. The pharmacologic actions of pomegranate juice include antiatherosclerotic, antibacterial, and antiproliferative properties [Anesini and Perez, 1993; Kim et al., 2002]. We recently found that when the polyphenol-rich pomegranate juice is consumed by the dam polyphenols from the juice are present

Polyphenols Protect against Neonatal Hypoxic-Ischemic Injury in the pup and protected the pup against $\mathrm{H}$-I brain injury [Loren et al., 2005]. Other studies have shown that the polyphenols caffeic acid phenylethyl ester and amentoflavone are also protective against neonatal $\mathrm{H}$-I brain injury [Wei et al., 2004; Shin et al., 2006]. To test the hypothesis that it is the polyphenols of pomegranate juice that are responsible for neuroprotection, we tested the effect of PPE in the neonatal H-I mouse model. Supplementation of PPE to the drinking water of pregnant and nursing dams resulted in significantly decreased $\mathrm{H}$-I-induced caspase- 3 activation. This suggests that it is the polyphenols of the pomegranate juice that are responsible for the neuroprotection.

To further investigate the role of polyphenols in neonatal H-I, we focused on the specific polyphenol resveratrol. This naturally occurring compound has been found to be neuroprotective in adult ischemia in rats when administered before the injury, but to our knowledge resveratrol has never been tested in neonatal H-I [Virgili and Contestabile, 2000; Huang et al., 2001; Gupta et al., 2002; Sinha et al., 2002]. By examining a variety of different concentrations at several different time points, we found that IP injection of resveratrol leads do decreased caspase- 3 activation in the $\mathrm{P} 7$ mouse in a concentration- and time-dependent manner. At doses of $200 \mu \mathrm{g} / \mathrm{kg}$ or greater, resveratrol leads to decreased caspase- 3 activation but only when resveratrol is injected prior to the injury. In addition to decreasing the caspase- 3 activation, resveratrol also decreases the calpain activation following neonatal H-I, suggesting that it works as a generally neuroprotective agent and not just on the apoptotic pathway.

In addition to finding that resveratrol is protective in the neonatal mouse, we also demonstrated that resveratrol protects the neonatal rat against $\mathrm{H}$-I-induced caspase 3 activation. Although the injury paradigm is similar in rats and mice, there are several neuroprotective agents that have been found to work only in one species. Since resveratrol has been found to protect against stroke in neonatal rats and mice as well as in adults, it could potentially be considered for further investigations in humans. Interestingly, we did not find resveratrol to be protective in the rat when given after the injury. Since the apoptotic cell death in the rat starts much later in the rat than in the mouse, and several drugs have been shown to be protective in the rat when given after the insult, we thought that resveratrol might follow the same pattern. The fact that resveratrol does not protect when given after the injury suggests that it is acting through proximal mechanisms in the cell death pathway initiated by H-I. One pathway that may be involved 
in the effects of polyphenols is via activation of the sirtuins such as SIRT1.

Polyphenols such as resveratrol may have beneficial effects on health via their antioxidant properties, suppression of inflammatory pathways, or other pathways such as activation of the sirtuin pathway [Aggarwal and Shishodia, 2004]. Included in the sirtuin family is SIRT1, a human protein deacetylase that promotes cell survival by mechanisms such as negatively regulating the p53 tumor suppressor [Luo et al., 2001; Vaziri et al., 2001; Langley et al., 2002], deacetylating the transcription factor FOXO3 [Brunet et al., 2004; Motta et al., 2004], repressing PPAR $\gamma$ signaling [Picard et al., 2004], and modulation of NF-к $\beta$-dependent transcription [Yeung et al., 2004]. Modulation of these pathways may provide a means to protect the developing brain against neonatal $\mathrm{H}-\mathrm{I}-$ induced brain damage. Recent studies show that polyphenols, including resveratrol, increase cell survival via activation of SIRT1 [Howitz et al., 2003]. Parker et al. [2005] found that increased sir2 gene dosage or treatment with resveratrol in Caenorhabditis elegans blocked neuronal dysfunction and cell death induced by polygluta- mine expansion. Suggesting that resveratrol may act through a similar pathway in mammals, resveratrol protected mammalian neuronal cell lines from mutant hungtingtin-induced cell death, and this effect was inhibited by sirtuin inhibitors [Parker et al., 2005]. There is also evidence that resveratrol can block axonal degeneration via SIRT1 in the mammalian peripheral nervous system [Araki et al., 2004]. While increasing evidence suggests that resveratrol and other polyphenols are neuroprotective, whether their protective actions in the CNS in vivo are via SIRT1 has not been directly assessed. Determining the mechanism of protection of resveratrol, pomegranate polyphenols, and other polyphenols may lead to novel insights into both pathogenesis and treatment of neonatal $\mathrm{H}-\mathrm{I}$ brain injury.

\section{Acknowledgements}

This research was supported by NIH NS35902 and by funds from the Stewart and Linda Resnick Revocable Trust.

\section{References}

Aggarwal BB, Shishodia S (2004): Suppression of the nuclear factor-kappaB activation pathway by spice-derived phytochemicals: reasoning for seasoning. Ann N Y Acad Sci 1030:434-441.

-Anesini C, Perez C (1993): Screening of plants used in Argentine folk medicine for antimicrobial activity. J Ethnopharmacol 39:119128.

-Araki T, Sasaki Y, Milbrandt J (2004): Increased nuclear NAD biosynthesis and SIRT1 activation prevent axonal degeneration. Science 305:1010-1013

Back SA (2001): Recent advances in human perinatal white matter injury. Prog Brain Res 132:131-147.

- Back SA, Rivkees SA (2004): Emerging concepts in periventricular white matter injury. Semin Perinatol 28:405-414.

Bianchini F, Vainio H (2003): Wine and resveratrol: mechanisms of cancer prevention? Eur J Cancer Prev 12:417-425.

Brunet A, Sweeney LB, Sturgill JF, Chua KF, Greer PL, Lin Y, Tran H, Ross SE, Mostoslavsky R, Cohen HY, Hu LS, Cheng HL, Jedrychowski MP, Gygi SP, Sinclair DA, Alt FW, Greenberg ME (2004): Stress-dependent regulation of FOXO transcription factors by the SIRT1 deacetylase. Science 303: 2011-2015.
Cheng Y, Deshmukh M, D’Costa A, Demaro JA, Gidday JM, Shah A, Sun Y, Jacquin MF, Johnson EM, Holtzman DM (1998): Caspase inhibitor affords neuroprotection with delayed administration in a rat model of neonatal hypoxic-ischemic brain injury. J Clin Invest 101:1992-1999.

- Cheng Y, Gidday JM, Yan Q, Shah AR, Holtzman DM (1997): Marked age-dependent neuroprotection by brain-derived neurotrophic factor against neonatal hypoxic-ischemic brain injury. Ann Neurol 41:521-529.

-Dajas F, Rivera F, Blasina F, Arredondo F, Echeverry C, Lafon L, Morquio A, Heizen $\mathrm{H}$ (2003): Cell culture protection and in vivo neuroprotective capacity of flavonoids. Neurotox Res 5:425-432.

Etus V, Altug T, Belce A, Ceylan S (2003): Green tea polyphenol (-)-epigallocatechin gallate prevents oxidative damage on periventricular white matter of infantile rats with hydrocephalus. Tohoku J Exp Med 200:203-209.

Faustino RS, Sobrattee S, Edel AL, Pierce GN (2003): Comparative analysis of the phenolic content of selected Chilean, Canadian and American Merlot red wines. Mol Cell Biochem 249:11-19.
- Gibson ME, Han BH, Choi J, Knudson CM, Korsmeyer SJ, Parsadanian M, Holtzman DM (2001): BAX contributes to apoptoticlike death following neonatal hypoxia- ischemia: evidence for distinct apoptosis pathways. Mol Med 7:644-655.

Gieron-Korthals M, Colon J (2005): Hypoxicischemic encephalopathy in infants: new challenges. Fetal Pediatr Pathol 24:105-120.

-Gil MI, Tomas-Barberan FA, Hess-Pierce B, Holcroft DM, Kader AA (2000): Antioxidant activity of pomegranate juice and its relationship with phenolic composition and processing. J Agric Food Chem 48:4581-4589.

- Gluckman PD, Wyatt JS, Azzopardi D, Ballard R, Edwards AD, Ferriero DM, Polin RA, Robertson CM, Thoresen M, Whitelaw A, Gunn AJ (2005): Selective head cooling with mild systemic hypothermia after neonatal encephalopathy: multicentre randomised trial. Lancet 365:663-670.

-Gulcan H, Ozturk IC, Arslan S (2005): Alterations in antioxidant enzyme activities in cerebrospinal fluid related with severity of hypoxic ischemic encephalopathy in newborns. Biol Neonate 88:87-91.

Gupta YK, Briyal S, Chaudhary G (2002): Protective effect of trans-resveratrol against kainic acid-induced seizures and oxidative stress in rats. Pharmacol Biochem Behav 71: 245-249. 
-Hagberg H, Bona E, Gilland E, Puka-Sundvall M (1997): Hypoxia-ischaemia model in the 7day-old rat: possibilities and shortcomings. Acta Paediatr Suppl 422:85-88.

Hall SS (2003): Longevity research. In vino vitalis? Compounds activate life-extending genes. Science 301:1165.

Hamrick SE, Ferriero DM (2003): The injury response in the term newborn brain: can we neuroprotect? Curr Opin Neurol 16:147154.

- Han BH, D’Costa A, Back SA, Parsadanian M, Patel S, Shah AR, Gidday JM, Srinivasan A, Deshmukh M, Holtzman DM (2000): BDNF blocks caspase-3 activation in neonatal hypoxia-ischemia. Neurobiol Dis 7:38-53.

-Han BH, DeMattos RB, Dugan LL, Kim-Han JS, Brendza RP, Fryer JD, Kierson M, Cirrito J, Quick K, Harmony JA, A ronow BJ, Holtzman DM (2001): Clusterin contributes to caspase3 -independent brain injury following neonatal hypoxia-ischemia. Nat Med 7:338343.

-Han BH, Xu D, Choi J, Han Y, Xanthoudakis S, Roy S, Tam J, Vaillancourt J, Colucci J, Siman R, Giroux A, Robertson GS, Zamboni R, Nicholson DW, Holtzman DM (2002): Selective, reversible caspase- 3 inhibitor is neuroprotective and reveals distinct pathways of cell death after neonatal hypoxic-ischemic brain injury. J Biol Chem 277:30128-30136.

-Hartman RE, Shah A, Fagan AM, Schwetye KE, Parsadanian M, Schulman RN, Finn MB, Holtzman DM (2006): Pomegranate juice decreases amyloid load and improves behavior in a mouse model of Alzheimer's disease. Neurobiol Dis 24:506-515.

- Hashimoto T, Yonetani M, Nakamura H (2003): Selective brain hypothermia protects against hypoxic-ischemic injury in newborn rats by reducing hydroxyl radical production. Kobe J Med Sci 49:83-91.

-Howitz KT, Bitterman KJ, Cohen HY, Lamming DW, Lavu S, Wood JG, Zipkin RE, Chung P, Kisielewski A, Zhang LL, Scherer B, Sinclair DA (2003): Small molecule activators of sirtuins extend Saccharomyces cerevisiae lifespan. Nature 425:191-196.

-Huang SS, Tsai MC, Chih CL, Hung LM, Tsai SK (2001): Resveratrol reduction of infarct size in Long-Evans rats subjected to focal cerebral ischemia. Life Sci 69:1057-1065.

-Kelawala NS, Ananthanarayan L (2004): Antioxidant activity of selected foodstuffs. Int J Food Sci Nutr 55:511-516.

Kil HY, Zhang J, Piantadosi CA (1996): Brain temperature alters hydroxyl radical production during cerebral ischemia/reperfusion in rats. J Cereb Blood Flow Metab 16:100-106.

Kim ND, Mehta R, Yu W, Neeman I, Livney T, Amichay A, Poirier D, Nicholls P, Kirby A, Jiang W, Mansel R, Ramachandran C, Rabi T, Kaplan B, Lansky E (2002): Chemopreventive and adjuvant therapeutic potential of pomegranate (Punica granatum) for human breast cancer. Breast Cancer Res Treat 71: 203-217.
Kopp P (1998): Resveratrol, a phytoestrogen found in red wine. A possible explanation for the conundrum of the 'French paradox'? Eur J Endocrinol 138:619-620.

Kostrzewa RM, Segura-Aguilar J (2003): Novel mechanisms and approaches in the study of neurodegeneration and neuroprotection. A review. Neurotox Res 5:375-383.

Langley E, Pearson M, Faretta M, Bauer UM, Frye RA, Minucci S, Pelicci PG, Kouzarides T (2002): Human SIR2 deacetylates p53 and antagonizes $\mathrm{PML} / \mathrm{p} 53$-induced cellular senescence. EMBO J 21:2383-2396.

Latruffe N, Delmas D, Jannin B, Cherkaoui Malki M, Passilly-Degrace P, Berlot JP (2002): Molecular analysis on the chemopreventive properties of resveratrol, a plant polyphenol microcomponent. Int J Mol Med 10:755760.

Leibovici D, Ritchie K, Ledesert B, Touchon J (1999): The effects of wine and tobacco consumption on cognitive performance in the elderly: a longitudinal study of relative risk. Int J Epidemiol 28:77-81.

Levites Y, Weinreb O, Maor G, Youdim MB, Mandel S (2001): Green tea polyphenol (-)epigallocatechin-3-gallate prevents $\mathrm{N}$-methyl-4-phenyl-1,2,3,6-tetrahydropyridine-induced dopaminergic neurodegeneration. J Neurochem 78:1073-1082.

Loren DJ, Seeram NP, Schulman RN, Holtzman DM (2005): Maternal dietary supplementation with pomegranate juice is neuroprotective in an animal model of neonatal hypoxicischemic brain injury. Pediatr Res 57: 858-864.

Luo J, Nikolaev AY, Imai S, Chen D, Su F, Shiloh A, Guarente L, Gu W (2001): Negative control of p53 by Sir2alpha promotes cell survival under stress. Cell 107:137-148.

- Motta MC, Divecha N, Lemieux M, Kamel C, Chen D, Gu W, Bultsma Y, McBurney M, Guarente L (2004): Mammalian SIRT1 represses forkhead transcription factors. Cell 116:551-563.

Ortiz D, Shea TB (2004): Apple juice prevents oxidative stress induced by amyloid-beta in culture. J Alzheimers Dis 6:27-30.

Parker JA, Arango M, Abderrahmane S, Lambert E, Tourette C, Catoire H, Neri C (2005): Resveratrol rescues mutant polyglutamine cytotoxicity in nematode and mammalian neurons. Nat Genet 37:349-350.

- Picard F, Kurtev M, Chung N, Topark-Ngarm A, Senawong T, Machado De Oliveira R, Leid M, McBurney MW, Guarente L (2004): Sirt1 promotes fat mobilization in white adipocytes by repressing PPAR-gamma. Nature 429:771-776.

Raval AP, Dave KR, Perez-Pinzon MA (2006): Resveratrol mimics ischemic preconditioning in the brain. J Cereb Blood Flow Metab 26:1141-1147.
Robertson CM, Finer NN, Grace MG (1989): School performance of survivors of neonatal encephalopathy associated with birth asphyxia at term. J Pediatr 114:753-760.

- Sato M, Suzuki Y, Okuda T, Yokotsuka K (1997): Contents of resveratrol, piceid, and their isomers in commercially available wines made from grapes cultivated in Japan. Biosci Biotechnol Biochem 61:1800-1805.

-Shankaran S, Laptook AR, Ehrenkranz RA, Tyson JE, McDonald SA, Donovan EF, Fanaroff AA, Poole WK, Wright LL, Higgins RD, Finer NN, Carlo WA, Duara S, Oh W, Cotten CM, Stevenson DK, Stoll BJ, Lemons JA, Guillet R, Jobe AH (2005): Whole-body hypothermia for neonates with hypoxic-ischemic encephalopathy. N Engl J Med 353: 1574-1584.

-Shankaran S, Woldt E, Koepke T, Bedard MP, Nandyal R (1991): Acute neonatal morbidity and long-term central nervous system sequelae of perinatal asphyxia in term infants. Early Hum Dev 25:135-148.

-Shin DH, Bae YC, Kim-Han JS, Lee JH, Choi IY, Son KH, Kang SS, Kim WK, Han BH (2006): Polyphenol amentoflavone affords neuroprotection against neonatal hypoxic-ischemic brain damage via multiple mechanisms. J Neurochem 96:561-572.

-Singh SK, Dua T, Tandon A, Kumari S, Ray G, Batra S (1999): Status of lipid peroxidation and antioxidant enzymes in hypoxic ischemic encephalopathy. Indian Pediatr 36: 561-566.

-Sinha K, Chaudhary G, Gupta YK (2002): Protective effect of resveratrol against oxidative stress in middle cerebral artery occlusion model of stroke in rats. Life Sci 71:655-665.

- Sweeney MI, Kalt W, MacKinnon SL, Ashby J, Gottschall-Pass KT (2002): Feeding rats diets enriched in lowbush blueberries for six weeks decreases ischemia-induced brain damage. Nutr Neurosci 5:427-431.

- Thoresen M, Satas S, Puka-Sundvall M, Whitelaw A, Hallstrom A, Loberg EM, Ungerstedt U, Steen PA, Hagberg H (1997): Post-hypoxic hypothermia reduces cerebrocortical release of NO and excitotoxins. Neuroreport 8: 3359-3362.

Tokusoglu O, Unal MK, Yemis F (2005): Determination of the phytoalexin resveratrol $\left(3,5,4^{\prime}\right.$-trihydroxystilbene) in peanuts and pistachios by high-performance liquid chromatographic diode array (HPLC-DAD) and gas chromatography-mass spectrometry (GC-MS). J Agric Food Chem 53:50035009.

Truelsen T, Thudium D, Gronbaek M (2002): Amount and type of alcohol and risk of dementia: the Copenhagen City Heart Study. Neurology 59:1313-1319.

Tsuji M, Wilson MA, Lange MS, Johnston MV (2004): Minocycline worsens hypoxic-ischemic brain injury in a neonatal mouse model. Exp Neurol 189:58-65. 
-Vaziri H, Dessain SK, Ng Eaton E, Imai SI, Frye RA, Pandita TK, Guarente L, Weinberg RA (2001): hSIR2(SIRT1) functions as an NADdependent p53 deacetylase. Cell 107:149159.

Virgili M, Contestabile A (2000): Partial neuroprotection of in vivo excitotoxic brain damage by chronic administration of the red wine antioxidant agent, trans-resveratrol in rats. Neurosci Lett 281:123-126.
Volpe J (1995): Neurology of the Newborn. Philadelphia, WB Saunders.

-Wei X, Zhao L, Ma Z, Holtzman DM, Yan C, Dodel RC, Hampel H, Oertel W, Farlow MR, Du Y (2004): Caffeic acid phenethyl ester prevents neonatal hypoxic-ischaemic brain injury. Brain 127:2629-2635.

West T, Atzeva M, Holtzman DM (2006): Caspase-3 deficiency during development increases vulnerability to hypoxic-ischemic injury through caspase-3-independent pathways. Neurobiol Dis 22:523-537.
Yeung F, Hoberg JE, Ramsey CS, Keller MD, Jones DR, Frye RA, Mayo MW (2004): Modulation of NF-kappaB-dependent transcription and cell survival by the SIRT1 deacetylase. EMBO J 23:2369-2380.

Yu C, Shin YG, Chow A, Li Y, Kosmeder JW, Lee YS, Hirschelman WH, Pezzuto JM, Mehta RG, van Breemen RB (2002): Human, rat, and mouse metabolism of resveratrol. Pharm Res 19:1907-1914. 